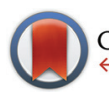

CrossMark \&lick for updates

Cite this: Dalton Trans., 2015, 44 10847

Received 28th January 2015, Accepted 13th March 2015

DOI: $10.1039 / c 5 d t 00396 b$

www.rsc.org/dalton

\title{
Non-aggregated Zn(II)octa(2,6-diphenylphenoxy) phthalocyanine as a hole transporting material for efficient perovskite solar cells $\uparrow$
}

\author{
F. Javier Ramos, ${ }^{a, c}$ M. Ince, ${ }^{\text {a,d }}$ M. Urbani, ${ }^{b, e}$ Antonio Abate, ${ }^{a}$ M. Grätzel, ${ }^{a}$ \\ Shahzada Ahmad, ${ }^{\mathrm{c}}$ T. Torres ${ }^{\star b, e}$ and Mohammad Khaja Nazeeruddin ${ }^{a, f}$
}

\begin{abstract}
A non-aggregated $\mathrm{Zn}(\Perp)$ octa(2,6-diphenylphenoxy) phthalocyanine (coded as $7 \mathbf{8 0}$ ) has been used as a hole-transporting material for perovskite solar cells. The cells were fabricated under three different configurations by changing the uptake solvent (chlorobenzene or toluene) and incorporating additives (bis(trifluoromethane) sulfonimide lithium salt (LiTFSI) and 4-tert-butylpyridine (TBP). A power conversion efficiency of $6.7 \%$ (AM1.5G standard conditions) was achieved for the best cell under optimized configuration.
\end{abstract}

\section{Introduction}

Dye sensitized solar cells (DSSCs) have been the focus of tremendous research efforts over the last two decades, as they represent a low-cost, effective and viable alternative to the actual silicon-based commercial modules to convert solar energy into electricity. ${ }^{1,2}$ In these devices, the light absorber is usually an organic molecule, inorganic complex, or quantum dots, adsorbed on the surface of a metal-oxide semiconductor (typically $\mathrm{TiO}_{2}$ nanoparticles). Despite these efforts, the power conversion efficiency (PCE) in the DSSC field has progressed only very slowly over the past few years, starting from $7 \%$ in $1991,{ }^{2} 10 \%$ in $1993,{ }^{3}$ to reach a maximum of $\sim 13 \%$ in $2014 .{ }^{4,5}$ An incredible breakthrough came recently with perovskite solar cells (PSCs), achieving efficiencies in the range of $12-20 \%$, which are already by far superior to the best DSSC device to date. ${ }^{6}$ Since the first example reported in 2009 with

\footnotetext{
${ }^{a}$ Laboratory of Photonics and Interfaces, Institute of Chemical Sciences and Engineering, Swiss Federal Institute of Technology (EPFL), Station 6, CH 1015 Lausanne, Switzerland. E-mail: mdkhaja.nazeeruddin@epfl.ch

${ }^{b}$ Universidad Autónoma de Madrid, Departamento de Química Orgánica, Cantoblanco, 28049 Madrid, Spain.E-mail: tomas.torres@uam.es

${ }^{c}$ Abengoa Research, C/Energía Solar no 1, Campus Palmas Altas-41014, Sevilla, Spain

${ }^{d}$ Mersin University, Department of Energy Systems Engineering, Faculty of Tarsus Technology, 33480 Mersin, Turkey

${ }^{e}$ Instituto Madrileño de Estudios Avanzados (IMDEA)-Nanociencia, c/Faraday, 9, Cantoblanco, 28049 Madrid, Spain

${ }^{f}$ Center of Excellence for Advanced Materials Research (CEAMR), King Abdulaziz University, Jeddah, Saudi Arabia

$\dagger$ Electronic supplementary information (ESI) available: Detailed photovoltaic parameters of the devices, current dynamic spectrum of TT80/PSC, copy of ${ }^{1} \mathrm{H}$ NMR, MS and HRMS spectra of TT80. See DOI: $10.1039 / \mathrm{c} 5 \mathrm{dt}$ t00396b
}

an efficiency of $3.8 \%,{ }^{7}$ the progress in this emerging technology has grown extremely fast in the mid-2012 and 2013 reaching over $12-16 \%$, with a record of $20.1 \%$ efficiency reported in early $2014{ }^{8,9}$ In these cells, the light absorbers are based on lead halide perovskite materials that exhibit broad absorption in the solar spectrum, excellent charge carrier mobility and low recombination. ${ }^{10,11}$ One of the important improvements of PSCs came from the replacement of the liquid redox mediator electrolyte, traditionally used in DSSC, ${ }^{12}$ by a p-type solid state hole transporting material (HTM) which is a crucial component for both long-term stability and further improvement in the efficiency of these cells. ${ }^{13}$ In fact, the best efficiencies of PSCs are presently obtained in conjunction with SpiroOMeTAD and polytertiaryarylamine (PTAA) polymers as the solid state HTM. However, such molecules are expensive to produce because of the complicated synthesis together with many purification steps, which constitute some important issues to facilitate large scale application and to produce devices at low cost. To this purpose, many efforts have been recently devoted to develop alternative HTMs, such as small organic molecules, polymers and inorganic salts, providing efficiencies in the range of $12 \% .{ }^{14-16}$ So far, very few of these new HTMs, however, can equal the performances obtained with the commercially available and widely used SpiroOMETAD.

Phthalocyanines (Pcs) have recently received much attention for their application in the field of DSSCs because of their stability and efficient light-harvesting ability throughout a large portion of the solar emission spectrum, especially in the red and the near-infrared regions. ${ }^{17-19}$ However, the tendency of Pcs to form aggregates on the metal oxide semiconductor surface and the lack of directionality in the excited state 


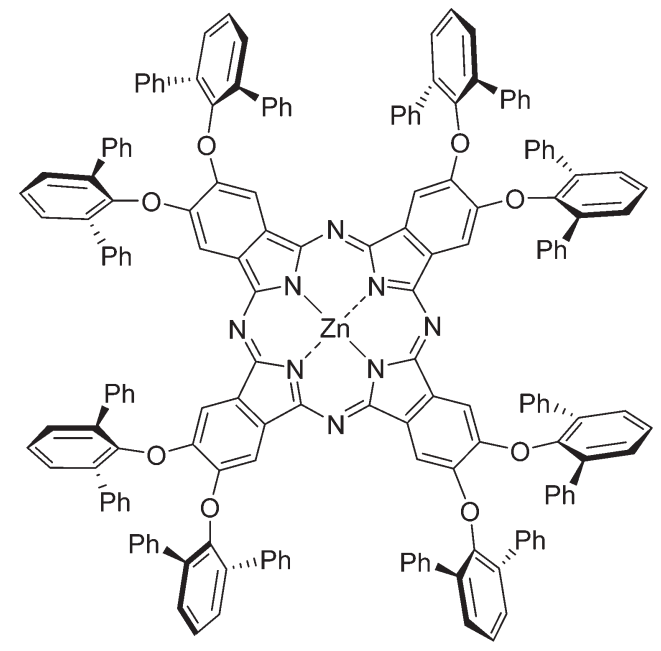

Fig. 1 Molecular structure of TT80.

limited the power conversion efficiency. ${ }^{20-25}$ To overcome these drawbacks, one of the major breakthroughs has been reported by Mori-Kimura's group in the design and development of Zn(II)Pc-based sensitizers by the introduction of bulky phenoxy units at the peripheral sites of the macrocycle which leads to the suppression of aggregation and results in important changes in the overall conversion efficiency for phthalocyanine sensitizers. ${ }^{26-29}$ Among them, a very high power conversion efficiency of $6.1 \%$ in this family of Pc sensitizers has been recently reported by our groups using a TT40 dye substituted with peripheral diphenylphenoxy groups and an ethynyl bridge between the anchoring carboxyl group and the Pc macrocycle. ${ }^{30,31}$

In the PSC field, only one example of HTM based on phthalocyanine has been recently reported by Kumar et al., who used an unsubstituted $\mathrm{Cu}-\mathrm{Pc}$ to achieve a PCE of $5 \% .{ }^{32}$ As a continuation of our efforts in the field of DSSC, bulky substituted non-aggregated phthalocyanine related to TT40 as organic HTM in PSCs was seen as an alternative. In the present study, a symmetrically substituted Zn(II)octa(2,6-diphenylphenoxy) phthalocyanine, namely TT80 (Fig. 1) has been synthesized and used for this purpose.

\section{Experimental section}

\section{(a) Materials}

All chemicals were purchased from Sigma Aldrich or Acros and used without further purification. $\mathrm{TiO}_{2}$ mesoporous paste (18NR-T) was purchased from Dyesol. 4,5-bis(2',6'-diphenylphenoxy)phthalonitrile ${ }^{26}$ and $\mathrm{CH}_{3} \mathrm{NH}_{3} \mathrm{I}^{33}$ were synthesized according to procedures previously reported in the literature. For the synthesis of the phthalonitrile precursor and TT80, the advancement of the reactions were monitored by a TLC plate employing aluminium sheets coated with silica gel 60 F254 (Merck). ${ }^{1} \mathrm{H}$ NMR (400 MHz) spectra were recorded using a Bruker Advance 400 spectrometer; chemical shifts $(\delta)$ are given in ppm relative to the residual solvent peak of the $\mathrm{CDCl}_{3}$ solvent (7.26 ppm). UV-Vis spectra were recorded on a HewlettPackard 8453 instrument. The FTIR spectrum was recorded on a Bruker Vector 22. MALDI-TOF MS/HRMS spectra (matrix: DCTB) were recorded on a Bruker Reflex III spectrometer; poly(ethyleneglycol) PEGNa2000 and PEGNa3400 were used as internal calibration references for HRMS MALDI-TOF spectra.

\section{(b) Synthesis of TT80}

Zinc(II) 2,3,9,10,16,17,23,24-octa(2',6'-diphenylphenoxy)phthalocyaninato(2-)- $N^{29}, N^{30}, N^{31}, N^{32}$ (TT80). A solution of 4,5bis(2',6'-diphenylphenoxy)phthalonitrile $(500 \mathrm{mg}, 0.81 \mathrm{mmol})$ and $\mathrm{ZnCl}_{2}(27 \mathrm{mg}, 0,2 \mathrm{mmol})$ in DMAE $(6 \mathrm{ml})$ was heated at reflux overnight under an argon atmosphere. After cooling to room temperature, the solvent was evaporated in vacuo and the crude mixture was washed with $\mathrm{MeOH}$. Purification by column chromatography on silica gel $\left(\mathrm{CH}_{2} \mathrm{Cl}_{2}\right)$ afforded the desired phthalocyanine TT80 as a green solid (153 mg, 30\%). ${ }^{1} \mathrm{H}$ NMR $\left(400 \mathrm{MHz}, \mathrm{CDCl}_{3}, 25{ }^{\circ} \mathrm{C}\right): \delta=7.7-7.6(\mathrm{~m}, 64 \mathrm{H}, \operatorname{Ar} H)$, 6.8-6.7 ppm (m, 48H, ArH); FTIR (film): $\nu\left(\mathrm{cm}^{-1}\right)=2921,2847$, 1605, 1487, 1452, 1414, 1396, 1269, 1202, 1095, 1025, 789; UV-Vis $\left(\mathrm{CHCl}_{3}\right): \lambda_{\max } / \mathrm{nm}(\log \varepsilon)=696$ (5.12), 665 (4.33), 626 (4.36), 347 (4.63); MS (MALDI-TOF, DCTB): $m / z$ (\%) 2528.7 (36), $2531.7(100)[\mathrm{M}]^{+}$; HRMS (MALDI-TOF, DCTB + PEGNa $2000+$ PEGNa 3400): $\mathrm{m} / \mathrm{z}$ calcd for $\mathrm{C}_{176} \mathrm{H}_{112} \mathrm{ZnN}_{8} \mathrm{O}_{8}: 2528.7889[\mathrm{M}]^{+}$; found 2528.7851 .

\section{(c) Device fabrication}

First, an FTO-coated glass (NSG10) was laser etched. After that, the samples were cleaned with Hellmanex solution $(2 \%$ in water), and rinsed successively with deionized water and then ethanol; subsequently they were washed using 2-propanol and then dried with compressed air. Before the compact layer deposition, the samples were cleaned by $\mathrm{UV} / \mathrm{O}_{3}$ for $30 \mathrm{~min}$. $\mathrm{A} \mathrm{TiO}_{2}$ blocking layer was deposited by spin coating (5000 rpm, $30 \mathrm{~s}$ ), employing a $2 \mathrm{M}$ aqueous solution of $\mathrm{TiCl}_{4}$; then the samples were heated at $70{ }^{\circ} \mathrm{C}$ for $30 \mathrm{~min}$ on a hot plate. Later, the $\mathrm{TiO}_{2}$ mesoporous paste (18NR-T) was diluted in absolute ethanol $(1: 3.5, \mathrm{w} / \mathrm{w})$, and then deposited by spin coating (5000 rpm, 30 s). Subsequently, the $\mathrm{TiO}_{2}$ films were subjected to a series of sintering: $5 \mathrm{~min}$ at $125{ }^{\circ} \mathrm{C}, 5 \mathrm{~min}$ at $325^{\circ} \mathrm{C}, 5 \mathrm{~min}$ at $375{ }^{\circ} \mathrm{C}, 15 \mathrm{~min}$ at $450{ }^{\circ} \mathrm{C}$ and finally for $15 \mathrm{~min}$ at $500{ }^{\circ} \mathrm{C}$. The perovskite fabrication was done by sequential deposition in agreement with the reported procedures. ${ }^{34} \mathrm{~A} \mathrm{PbI}_{2}$ film was deposited by spin coating ( $6500 \mathrm{rpm}$ for $30 \mathrm{~s}$ ) from a solution of $\mathrm{PbI}_{2}$ in $\mathrm{N}, \mathrm{N}$-dimethylformamide (DMF) maintained at $70{ }^{\circ} \mathrm{C}$ to avoid any precipitation. After lead iodide deposition, the samples were annealed at $70{ }^{\circ} \mathrm{C}$ for $15-20 \mathrm{~min}$, and then cooled down to RT. For $\mathrm{CH}_{3} \mathrm{NH}_{3} \mathrm{PbI}_{3}$ formation, $\mathrm{PbI}_{2}$ films were dipped in $\mathrm{CH}_{3} \mathrm{NH}_{3} \mathrm{I}$ solution (8 $\mathrm{mg}$ per $\mathrm{mL}$ of 2-propanol) for $20 \mathrm{~s}$ until a change of color from yellow to dark brown was observed, indicating the perovskite formation. After that, samples were successively rinsed with 2-propanol, dried and annealed again for $15 \mathrm{~min}$. Regarding the hole transporting material deposition, TT80 was dissolved in chlorobenzene $\left(10 \mathrm{mg} \mathrm{mL}{ }^{-1}\right)$, filtered and spin-coated at $1000 \mathrm{rpm}$ for $30 \mathrm{~s}$. 
After optimization of the devices with TT80, more concentrated solutions were found necessary: $30 \mathrm{mg}$ of TT80 were dissolved in $1 \mathrm{~mL}$ of the solvent (chlorobenzene or toluene); LiTFSI (from a stock solution $170 \mathrm{mg} \mathrm{mL}^{-1}$ in acetonitrile) and 4-tert-butylpyridine were employed as additives at concentrations of $0.011 \mathrm{M}$ and $0.06 \mathrm{M}$, respectively; these solutions were also filtered and deposited by spin coating (2000 rpm, $30 \mathrm{~s}$ ). Finally, for the counter electrode, gold was deposited by thermal evaporation to form of an $80 \mathrm{~nm}$ thickness Au-coated layer.

\section{(d) Photovoltaic characterization procedures}

To study the photovoltaic performance, the current-voltage curve was measured using a $450 \mathrm{~W}$ Xe lamp (Oriel) with a Schott K113 Tempax sunlight filter (Praezisions Glas \& Optik $\mathrm{GmbH}$ ) while a digital source meter (Keithly Model 2400) was used to apply the voltage to the cell. For IPCE characterization, a $300 \mathrm{~W}$ Xe lamp (ILC Technology) was linked to a Gemini180 monochromator (Jobin Yvon Ltd) to tune the light beam accordingly. $10 \%$ of white light bias was applied using an array of white LEDs as it is commonly extended to perovskite solar cells. A Model SR830 DSP Lock-in amplifier (Standford Research Systems) was utilized to record the performance. For both $J-V$ and IPCE measurements, the active area was fixed to $0.159 \mathrm{~cm}^{2}$ using a metal mask.

\section{Results and discussion}

\section{(a) Synthesis and characterisation of TT80}

Symmetrical substituted Zn(II)Pc, TT80, was prepared by cyclotetramerization reaction of 4,5-bis $\left(2^{\prime}, 6^{\prime}\right.$ diphenylphenoxy) phthalonitrile in $\mathrm{N}, \mathrm{N}$-dimethylaminoethanol (DMAE) in the presence of $\mathrm{ZnCl}_{2}$. Purification by column chromatography afforded TT80 in 30\% yield as a green solid. TT80 was fully characterized by mass spectrometry, ${ }^{1} \mathrm{H}-\mathrm{NMR}$, UV-Vis and FTIR spectroscopy. Unlike the typical broadened peaks observed in the ${ }^{1} \mathrm{H}$ NMR spectra of phthalocyanines in non-coordinating solvents due to the tendency of their $\pi$-system to form aggregates, TT80 gave rise to well-resolved spectra in $\mathrm{CDCl}_{3}$ because of the absence of aggregation (see Fig. S2 $\dagger$ ). In addition, TT80 displays an unusual deep green colour in the solid state, in contrast to the typical dark blue one of common Pcs. Fig. 2 shows the UV-Vis spectrum of TT80 in $\mathrm{CHCl}_{3}$ solution which exhibits an intense $\mathrm{Q}$ band at $696 \mathrm{~nm}$.

\section{(b) Photovoltaic performances}

The photovoltaic data of the cells obtained with phthalocyanine TT80 as the HTM, employing different uptake solvents and additives are summarized in Table 1, and the corresponding $J-V$ curves are depicted in Fig. 3. For comparison purposes, a benchmark PSC cell using Spiro-OMeTAD as the HTM was also prepared, and its photovoltaic performances are reported in Table 1.

Due to the great solubility of perovskite in most of the solvents, only some non-polar solvents can be used in the solu-

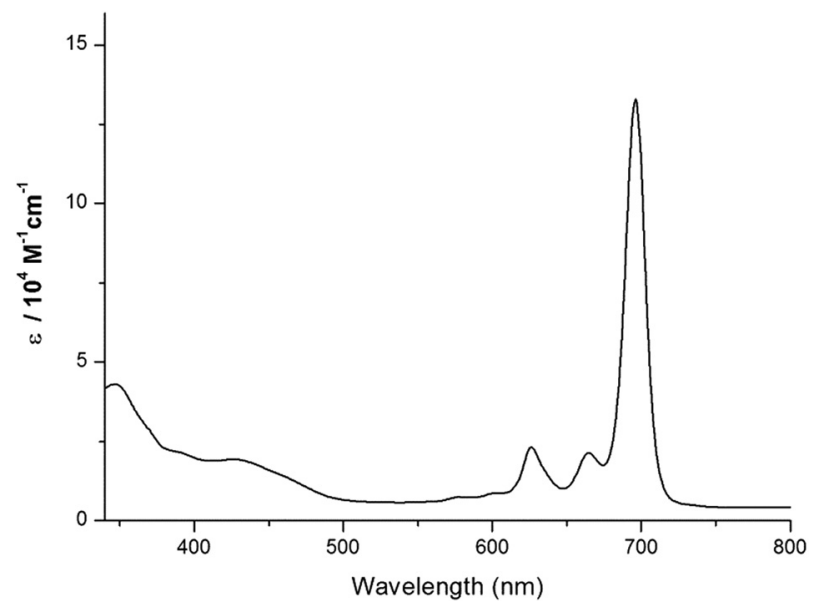

Fig. 2 UV-Vis absorption spectrum of $\mathrm{TT} 80$ in $\mathrm{CHCl}_{3}$ solution $(\sim 1 \times$ $\left.10^{-5} \mathrm{M}\right)$.

tion processed deposition of the HTM like benzene, chlorobenzene or toluene when regular structures are prepared. Chlorobenzene has been demonstrated as the most effective solvent for several small molecules ${ }^{34,35}$ although toluene showed a better response for other systems. ${ }^{36}$ In this context, we first chose chlorobenzene as the uptake solvent for TT80, and then studied the influence of additives toward the performance of the device in each configuration. When TT80 was employed without any additive, the measured efficiencies remained low $(\mathrm{PCE}=2.57 \%)$. With the aim to improve the efficiency of the TT80 system, bis(trifluoromethane) sulfonimide lithium salt (LiTFSI) and 4-tert-butylpyridine (TBP) were considered. We observed a considerable improvement of all the photovoltaic parameters upon incorporation of those additives, the champion cell showing a remarkable advance in terms of open-circuit voltage, short circuit current and fill factor $\left(V_{\mathrm{OC}}=797.4 \mathrm{mV} ; J_{\mathrm{SC}}=16.35 \mathrm{~mA} \mathrm{~cm}{ }^{-2} ; \mathrm{FF}=50.3 \%\right)$ achieving an overall PCE of $6.7 \%$. Such improvements were also observed for perovskite solar cells using other HTMs based on small molecules such as Spiro-OMeTAD9, ${ }^{34,37}$ or conductive polymers such as PTAA. ${ }^{36,38}$

Next, an analogous device was fabricated under the same conditions using this time toluene as the uptake solvent instead of chlorobenzene, in order to investigate the effect on the photovoltaic performance of the cell. When the infiltration of perovskite inside the mesoporous scaffold and the crystal formation of perovskite, both inside the mesoporous material, and onto the capping layer are homogeneous and properly grown, then $J_{\mathrm{SC}}$ is independent of the solvent used because it is only related to the absorber material as it is seen in this case for both solvents. The $V_{\text {OC }}$ is also independent of the solvent because it is only related to the HOMO level of the molecule, and concentration of the additives which was the same in both cases. While the $J_{\mathrm{SC}}$ and $V_{\mathrm{OC}}$ were indeed similar for both cells, the device made from toluene solution showed a significantly lower fill factor $(\mathrm{FF}=45.0 \%$ versus $50.3 \%$ ) 
Table 1 Photovoltaic parameters ${ }^{a}$ obtained for the perovskite solar cells employing phthalocyanine TT80 and benchmark Spiro-OMeTAD as holetransporting materials (HTMs). $P_{\text {in, }}$ incident intensity of simulated AM1.5G solar light ${ }^{b}$

\begin{tabular}{lllllrr}
\hline HTM & Additives & Uptake solvent & $P_{\text {in }}\left[\mathrm{mW} \mathrm{cm}^{-2}\right]$ & $J_{\text {SC }}\left(\mathrm{mA} \mathrm{cm}^{-2}\right)$ & $V_{\text {OC }}(\mathrm{mV})$ & FF $(\%)$ \\
\hline TT80 & - & PhCl & 96.8 & 11.90 & 578 & 36.2 \\
TT80 & LiTFSI + TBP & PhCl & 97.4 & 16.35 & 797 & 50.3 \\
TT80 & LiTFSI + TBP & PhCH $_{3}$ & 97.4 & 16.91 & 796 & 45.0 \\
Spiro-OMeTAD & LiTFSI + TBP & PhCl & 96.5 & 18.53 & 910 & 59.2
\end{tabular}

${ }^{a}$ The values presented were obtained for the best device in each configuration. For each configuration, two to four devices of equal quality were tested, and the uncertainties of $\eta$ values were within $1-6 \%$ (see Table S1 in the ESI for details). ${ }^{b}$ For 1 sun irradiation, $P_{\text {in }}=100 \mathrm{~mW} \mathrm{~cm}^{-2}$.

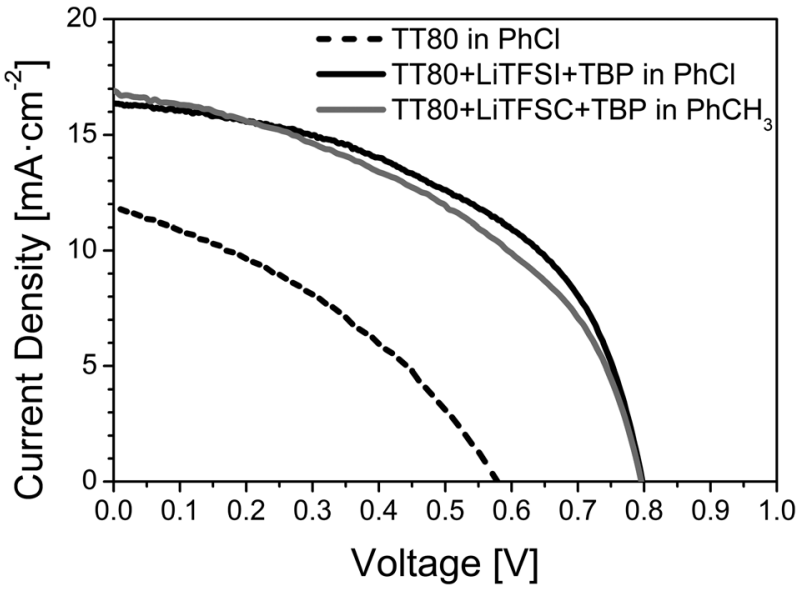

Fig. $3 \mathrm{~J}-V$ curves under simulated full sun illumination (AM1.5G) for the three cells made with TT80 as HTM using different solvents and additives $\left(\mathrm{PhCl}=\right.$ chlorobenzene; $\mathrm{PhCH}_{3}=$ toluene; TBP $=4$-tertbutylpyridine).

responsible for its lower overall efficiency (6.2\% versus $6.7 \%)$. We assume that during the spin-coating process, the faster evaporation of toluene in comparison with chlorobenzene results in a more irregular distribution of the HTM layer and less intimate contact with the perovskite, which explains mostly why the fill factor was lower for the device made from toluene solution. In addition, we studied the effect of the spincoating speed (500 or $2000 \mathrm{rpm}$ for $30 \mathrm{~s}$ ) on the photovoltaic performances obtained for the PSC/TT80 devices (see Table S2 of the ESI $\dagger$ ). For both solvents the best efficiencies were obtained for the devices prepared at $2000 \mathrm{rpm}$, for which we estimated a HTM thickness of $c a$. $150 \mathrm{~nm}$. When a slower spinning speed was used $(500 \mathrm{rpm})$, thicker HTM films were expected but the performances of the devices were systematically lower, especially when chlorobenzene solvent was employed.

The IPCE spectrum obtained for the best device in the optimized configuration (TT80 + LiTFSI + TBP in chlorobenzene as the uptake solvent) is shown in Fig. 4. As expected, no evidence of extra absorption coming from the TT80 molecule is observed, concluding that the only absorber in the system is indeed the perovskite, and phthalocyanine works only as a HTM.

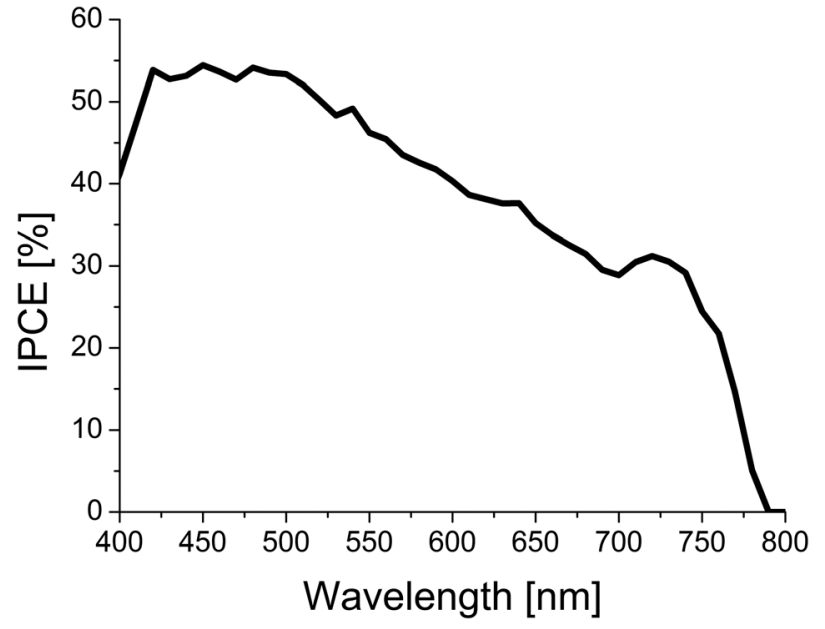

Fig. 4 Incident photon-to-photocurrent efficiency for the best cell made with TT80 under optimized configuration (TT80 + LiTFSI + TBP in $\mathrm{PhCl}$.

\section{Conclusions}

We have reported in this study a non-aggregated phthalocyanine TT80 used as a hole-transporting material (HTM) for perovskite solar cells. With the optimized conditions for the uptake solvent and the use of additives, the best cell achieved a maximum power conversion efficiency of $6.7 \%$ under AM1.5G standard conditions. Hence, this work demonstrates that phthalocyanine can be used as a HTM for perovskite solar cells, and opens up a route to engineer new systems based on these highly stable and hydrophobic molecules to enhance power conversion efficiency and overall stability of the perovskite solar cells.

\section{Acknowledgements}

We are grateful for the financial support of the MEC, Spain (CTQ2014-52869/BQU), Comunidad de Madrid, Spain (FOTOCARBON, S2013/MIT-2841), and the European Union within the FP7-ENERGY-2012-1, nr. 309194-2, GLOBALSOL project. M. K. N. thanks the European Union for funding 
within the Seventh Framework Program [FP7/2007-2013] under the grant agreement no. 604032 of the MESO project.

\section{Notes and references}

1 A. Hagfeldt, G. Boschloo, L. Sun, L. Kloo and H. Pettersson, Chem. Rev., 2010, 110, 6595-6663.

2 B. O'Regan and M. Grätzel, Nature, 1991, 353, 737-740.

3 M. K. Nazeeruddin, A. Kay, I. Rodicio, R. Humphry-Baker, E. Mueller, P. Liska, N. Vlachopoulos and M. Grätzel, J. Am. Chem. Soc., 1993, 115, 6382-6390.

4 S. Mathew, A. Yella, P. Gao, R. Humphry-Baker, B. F. E. Curchod, N. Ashari-Astani, I. Tavernelli, U. Rothlisberger, M. K. Nazeeruddin and M. Grätzel, Nat. Chem., 2014, 6, 242-247.

5 M. Urbani, M. Grätzel, M. K. Nazeeruddin and T. Torres, Chem. Rev., 2014, 114, 12330-12396.

6 M.-E. Ragoussi and T. Torres, Chem. Commun., 2015, 51, 3957-3972.

7 A. Kojima, K. Teshima, Y. Shirai and T. Miyasaka, J. Am. Chem. Soc., 2009, 131, 6050-6051.

8 M. A. Green, A. Ho-Baillie and H. J. Snaith, Nat. Photonics, 2014, 8, 506-514.

9 M. M. Lee, J. Teuscher, T. Miyasaka, T. N. Murakami and H. J. Snaith, Science, 2012, 338, 643-647.

10 V. W. Bergmann, S. A. L. Weber, F. Javier Ramos, M. K. Nazeeruddin, M. Grätzel, D. Li, A. L. Domanski, I. Lieberwirth, S. Ahmad and R. Berger, Nat. Commun., 2014, 5, 5001.

11 E. Guillén, F. J. Ramos, J. A. Anta and S. Ahmad, J. Phys. Chem. C, 2014, 118, 22913-22922.

12 C. Xu, J. Wu, U. V. Desai and D. Gao, Nano Lett., 2012, 12, 2420-2424.

13 B. Cai, Y. Xing, Z. Yang, W.-H. Zhang and J. Qiu, Energy Environ. Sci., 2013, 6, 1480-1485.

14 J. Liu, Y. Wu, C. Qin, X. Yang, T. Yasuda, A. Islam, K. Zhang, W. Peng, W. Chen and L. Han, Energy Environ. Sci., 2014, 7, 2963-2967.

15 H. Li, K. Fu, A. Hagfeldt, M. Grätzel, S. G. Mhaisalkar and A. C. Grimsdale, Angew. Chem., Int. Ed., 2014, 53, 40854088.

16 H. Choi, S. Park, S. Paek, P. Ekanayake, M. K. Nazeeruddin and J. Ko, J. Mater. Chem. A, 2014, 2, 19136-19140.

17 G. de la Torre, C. G. Claessens and T. Torres, Chem. Commun., 2007, 2000-2015.

18 J. Mack and N. Kobayashi, Chem. Rev., 2011, 111, 281-321.

19 C. G. Claessens, U. Hahn and T. Torres, Chem. Rec., 2008, 8, 75-97.
20 M. V. Martínez-Díaz and T. Torres, in Handbook of Porphyrin Science, ed. K. M. Kadish, K. M. Smith and R. Guilard, World Science Publishers, 2010, vol. 10, pp. 141-181.

21 M. V. Martinez-Diaz, G. de la Torre and T. Torres, Chem. Commun., 2010, 46, 7090-7108.

22 M. V. Martinez-Diaz, M. Ince and T. Torres, Monatsh. Chem., 2011, 142, 699-707.

23 L. Giribabu, K. Sudhakar and V. Velkannan, Curr. Sci., 2012, 102, 991-1000.

24 M. G. Walter, A. B. Rudine and C. C. Wamser, J. Porphyrins Phthalocyanines, 2010, 14, 759-792.

25 M.-E. Ragoussi, M. Ince and T. Torres, Eur. J. Org. Chem., 2013, 6475-6489.

26 S. Mori, M. Nagata, Y. Nakahata, K. Yasuta, R. Goto, M. Kimura and M. Taya, J. Am. Chem. Soc., 2010, 132, 40544055.

27 M. Kimura, H. Nomoto, N. Masaki and S. Mori, Angew. Chem., Int. Ed., 2012, 51, 4371-4374.

28 M. Kimura, H. Nomoto, H. Suzuki, T. Ikeuchi, H. Matsuzaki, T. N. Murakami, A. Furube, N. Masaki, M. J. Griffith and S. Mori, Chem. - Eur. J., 2013, 19, 74967502.

29 T. Ikeuchi, H. Nomoto, N. Masaki, M. J. Griffith, S. Mori and M. Kimura, Chem. Commun., 2014, 50, 1941-1943.

30 M.-E. Ragoussi, J.-J. Cid, J.-H. Yum, G. de la Torre, D. Di Censo, M. Grätzel, M. K. Nazeeruddin and T. Torres, Angew. Chem., Int. Ed., 2012, 51, 4375-4378.

31 M.-E. Ragoussi, J.-H. Yum, A. K. Chandiran, M. Ince, G. de la Torre, M. Grätzel, M. K. Nazeeruddin and T. Torres, ChemPhysChem, 2014, 15, 1033-1036.

32 C. V. Kumar, G. Sfyri, D. Raptis, E. Stathatos and P. Lianos, RSC Adv., 2015, 5, 3786-3791.

33 J.-H. Im, C.-R. Lee, J.-W. Lee, S.-W. Park and N.-G. Park, Nanoscale, 2011, 3, 4088-4093.

34 J. Burschka, N. Pellet, S.-J. Moon, R. Humphry-Baker, P. Gao, M. K. Nazeeruddin and M. Grätzel, Nature, 2013, 499, 316-319.

35 P. Qin, S. Paek, M. I. Dar, N. Pellet, J. Ko, M. Grätzel and M. K. Nazeeruddin, J. Am. Chem. Soc., 2014, 136, 85168519.

36 J. Krüger, R. Plass, L. Cevey, M. Piccirelli, M. Grätzel and U. Bach, Appl. Phys. Lett., 2001, 79, 2085-2087.

37 H.-S. Kim, C.-R. Lee, J.-H. Im, K.-B. Lee, T. Moehl, A. Marchioro, S.-J. Moon, R. Humphry-Baker, J.-H. Yum, J. E. Moser, M. Grätzel and N.-G. Park, Sci. Rep., 2012, 2, 591.

38 J. H. Heo, S. H. Im, J. H. Noh, T. N. Mandal, C.-S. Lim, J. A. Chang, Y. H. Lee, H.-j. Kim, A. Sarkar, M. K. Nazeeruddin, M. Grätzel and S. II Seok, Nat. Photonics, 2013, 7, 486-491. 